DOI: $10.34185 / 1991-7848.2018 .01 .11$

УДК: $669.15 * 24 * 26-194: 669.046 .001 .8$

И.Р. Снигура, Д.Н. Тогобицкая

\title{
ПРОГНОЗИРОВАНИЕ ТЕМПЕРАТУР ПЛАВЛЕНИЯ И КРИСТАЛЛИЗАЦИИ ХРОМОНИКЕЛЕВЫХ СТАЛЕЙ
}

\begin{abstract}
В настоящее время наиболее широко используются методы доводки стали по химическому составу посредством процессов легирования как одной добавкой, так и комплексными лигатурами для формирования требуемых свойств металлопродукции. С целью получения качественно новых характеристик хромоникелевых сталей необходимо расширять номенклатуру используемых легирующих добавок с учетом эффективности их усвоения. Безусловно подбор вводимых добавок $в$ сталь относится к сложному многостадийному физико-химическому процессу, который в первую очередь должен обеспечить условия для максимальной степени усвоения и равномерномерности распределения присаживаемой лигатуры с минимальными энергетическими и сырьевыми потерями. Температурный фактор является одним из важнейших катализаторов процессов усвоения легирующих, модифицирующих и рафинирующих добавок, эффективности протекания реакций и распределения ведущих элементов между металлом и шлаком, а также наиболее информативным показателем для принятия решений по управлению температурным режимом плавки. Основываясь на особенностях строения металлических расплавов выдвинута идея о подходе к выбору легирующих добавок с учетом их микронеоднородности. В работе предложены математические модели для прогнозирования температур ликвидус и солидус хромоникелевых сталей с использованием концепции направленной химической связи. Результаты исследований рекомендуются $к$ использованию в промышленных условиях с целью научно-обоснованного выбора легирующих добавок и направленного формирования конечного продукта, что обеспечит снижения энергетических затрат посредством интеграции разработанных моделей в АСУТП сталеплавильного производства.
\end{abstract}

Ключевые слова: хромоникелевые стали, параметры межатомного взаимодействия, микролегирование, температура ликвидус и солидус, прогнозирование.

\section{Состояние вопроса}

Хромоникелевые стали являются одними из наиболее востребованных на отечественных и зарубежных рынках сталеплавильной продукции. Однако динамически растущие требования, предъявляемые к качеству и эксплуатационным характеристикам сталей, приводят к поиску путей существенной модернизации хромоникелевых сталей. В настоящее время наиболее широко используются методы доводки стали по химическому составу посредством процессов легирования как одной добавкой, так и комплексными лигатурами для формирования требуемых свойств металлопродукции.

С целью получения качественно новых характеристик хромоникелевых сталей необходимо расширять номенклатуру используемых легирующих добавок с учетом эффективности их усвоения. Как показывает анализ литературных данных [1-5] за последнее время, например, повысился интерес к использованию бора в качестве легирующей и микролегирующей добавки в сталеплавильном производстве, поскольку его применение позволяет не только повысить эксплуатационные свойства сталей, но и заменить применяемые дорогостоящие добавки.

Безусловно подбор вводимых добавок в сталь относится к сложному многостадийному физико-химическому процессу, который в первую очередь должен обеспечить условия для максимальной степени усвоения и равномерномерности распределения присаживаемой лигатуры с минимальными энергетическими и сырьевыми потерями. Температурный фактор является одним из важнейших катализаторов процессов усвоения легирующих, модифицирующих и рафинирующих добавок, эффективности протекания реакций и

(c) Снигура И.Р., Тогобицкая Д.Н., 2018 
распределения ведущих элементов между металлом и шлаком, а также наиболее информативным показателем для принятия решений по управлению температурным режимом плавки. Важность учета температурных условий, как лимитирующего звена в получении высококачественного и конкурентоспособного металлопродукта также отмечена в работах И.В. Гаврилина [6], И.П. Казачкова [7], С.Л. Макурова [8], А.М. Скребцова [9] и многих других ученых. Таким образом, актуальным является знание и оперативные методы определения температур плавления и кристаллизации, учитывающие химический состав стали и межатомное взаимодействие между компонентами расплава позволяющие описать неразрывную цепь «состав-структура-свойства».

\section{Изложение основного материала}

Согласно современным представлениям о строении металлических расплавов, базирующихся на кластерной модели [10], однокомпонентные и многокомпонентные системы - микронеоднородные по своей природе. Структурными составляющими металлического расплава выступают кластеры - структурно-упорядоченные микрообласти, которые по своему строению напоминают кристалл и весьма устойчивые, чередующиеся с разупорядоченными зонами (атомы находятся в хаотичном движении идентичному газовому). В сталеплавильном производстве для получения гомогенного металлического расплава, как показателя качества металлопродукции, еще на этапе выбора легирующей добавки следует учитывать ее микронеоднородность. В случае, когда при легировании была некорректно выбрана вводимая добавка и процесс растворения ее реализован неполностью, вероятнее всего будут существовать кластеры легирующей добавки, которые послужат центрами кристаллизации. Сегрегация кластеров в стали приводит к росту неоднородности и образованию областей с повышенной хрупкостью, что значительно ухудшает служебные свойства готовой металлопродукции.

Поскольку железо является основой всех сталей и сплавов, на рис.1. исходя из температурного диапазона существования кластеров однокомпонентных металлических расплавов, как потенциальных легирующих добавок выделена область наиболее рациональных для применения, что позволит избежать неоправданного перегрева металла и повысить степень усвоения добавки. Таким образом к эффективным легирующим элементам следует отнести бор, молибден, титан, ванадий.

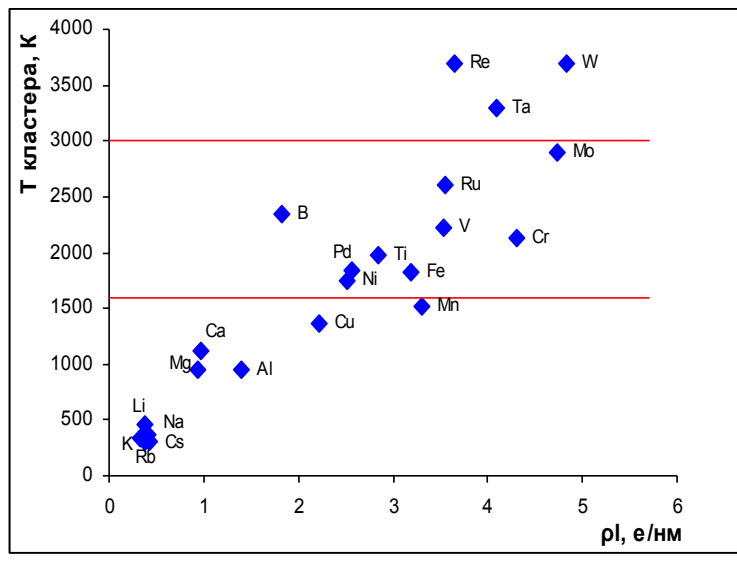

a)

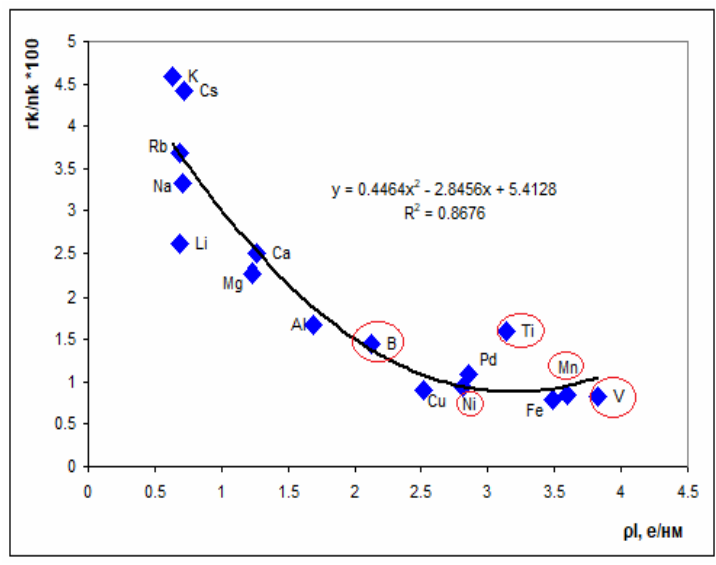

б)

Рисунок 1 - Зависимость: а) - температуры существования кластера однокомпонентных металлических расплавов от параметра направленной зарядовой плотности $\mathrm{pl}$; б) характеристики структуры кластера от от параметра направленной зарядовой плотности $\rho \mathrm{l}$ 
Не случайно относительная характеристика объема, приходящегося на один атом в кластере (rk/nk*100) упоминается авторами работы [11], поскольку она связана с направленной зарядовой плотностью, что позволяет рассматривать $\rho \mathrm{l}$ в качестве физико-химического критерия оценки микронеоднородности металлических расплавов.

В настоящей работе рассмотрено прогнозирование температур ликвидус и солидус хромоникелевых сталей с использованием оригинальной концепции направленной химической связи Приходько Э.В., которая рассматривает расплав, как химически единую систему [12]. Принцип подхода базируется на вводе в связь между составом и свойствами расплавов промежуточного звена в виде комплекса интегральных модельных параметров межатомного взаимодействия, которые характеризуют химическое и структурное состояние исследуемого материала ( $\mathrm{Z}^{\mathrm{y}}$ - параметр зарядового состояния системы, e; $\mathrm{d}$ среднестатистическое межъядерное расстояние, $10^{-1} \mathrm{Hm}$; $\operatorname{tg} \alpha$ - константа для каждого сплава, характеризующая изменение радиуса иона при изменении его заряда; $\rho$ - направленная зарядовая плотность, е/нм).

Объектом исследования в данной работе выступают хромоникелевые стали с содержанием основных элементов $\mathrm{Cr}$, Ni от 0 до 30\%, химический состав, которых приведен в табл. 1.

Таблица 1

Фрагмент выборки данных о химическом составе исследуемых сталей

\begin{tabular}{|l|l|l|l|l|l|l|l|l|l|l|l|l|}
\hline $\begin{array}{l}\text { № } \\
\text { П/П }\end{array}$ & $\mathrm{C}$ & $\mathrm{Si}$ & $\mathrm{Mn}$ & $\mathrm{P}$ & $\mathrm{S}$ & $\mathrm{Cr}$ & $\mathrm{Mo}$ & $\mathrm{Ni}$ & $\mathrm{N}$ & $\mathrm{Ti}$ & $\mathrm{Nb}$ & $\mathrm{Fe}$ \\
\hline 1 & 0.063 & 0.29 & 1.45 & 0.022 & 0.003 & 17.9 & 0.18 & 9.29 & 0.06 & 0 & 0.47 & 70.272 \\
\hline 2 & 0.055 & 0.7 & 1.77 & 0.019 & 0.004 & 17 & 2.13 & 11.9 & 0.026 & 0.18 & 0 & 66.216 \\
\hline 3 & 0.99 & 0.36 & 0.12 & 0.005 & 0.003 & 10.1 & 0.02 & 0.02 & 0 & 0 & 0 & 88.382 \\
\hline 4 & 0.05 & 0.63 & 1.75 & 0.01 & 0.004 & 25.8 & 0.35 & 20.7 & 0.039 & 0 & 0 & 50.667 \\
\hline 5 & 0.41 & 1 & 1.34 & 0.007 & 0.01 & 25.2 & 0.08 & 20.6 & 0.022 & 0 & 0 & 51.331 \\
\hline
\end{tabular}

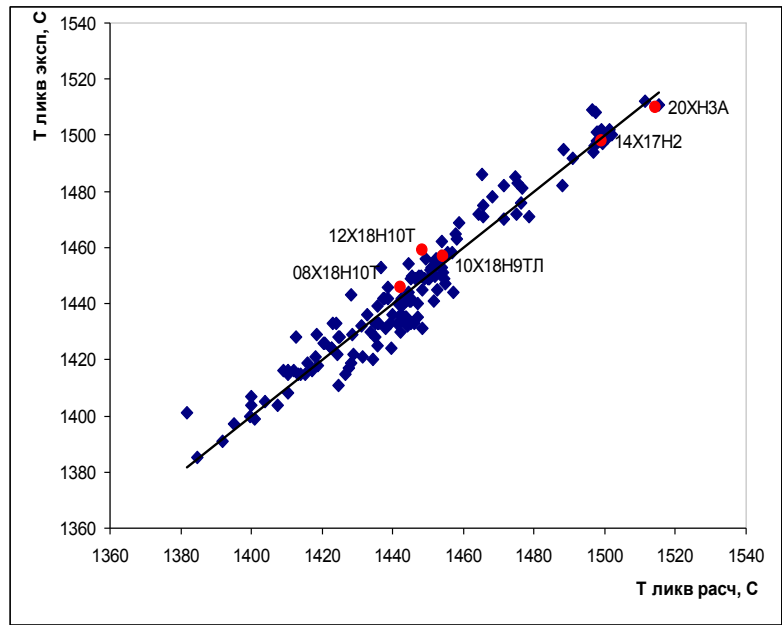

a)

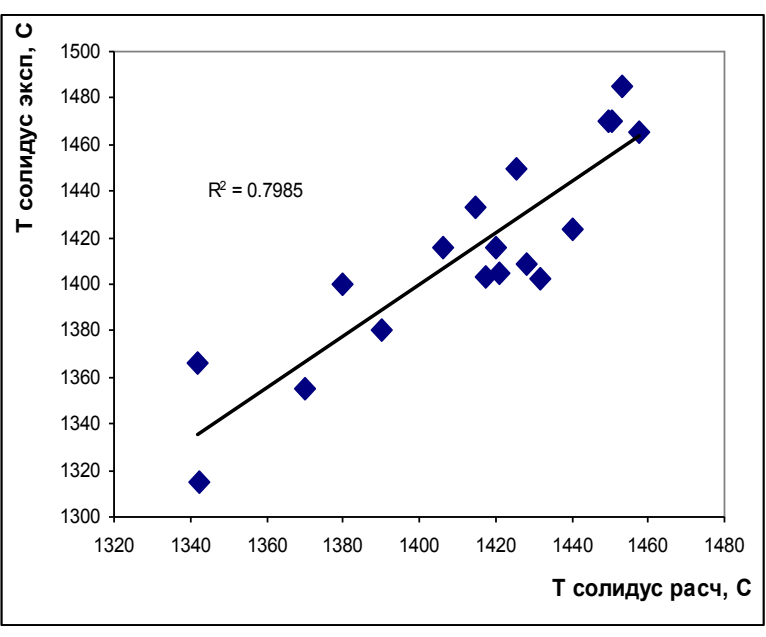

б)

Рисунок 2 - Сравнение: а) - экспериментальных и расчетных значений температуры ликвидус хромоникелевых сталей, а также данных, не вошедших в исходную выборку; б) - экспериментальных и расчетных значений температуры солидус хромоникелевых сталей

Анализ взаимосвязей температуры ликвидус хромоникелевых сталей с параметрами межатомного взаимодействия позволил установить, что наиболее информативными являются $\mathrm{Z}^{\mathrm{y}}, \mathrm{d}, \operatorname{tg} \alpha$, которые выбраны в качестве модельных формируют основу прогнозной модели для 
определения температуры плавления. Таким образом, модель для прогнозирования температуры ликвидус с коэффициентом детерминированности $\mathrm{R}^{2}=0,939$ имеет вид: $\mathrm{T}_{\mathrm{L}}=f\left(\mathrm{Z}^{\mathrm{y}}\right.$, $\mathrm{d}, \operatorname{tg} \alpha)$. Разработанная модель для прогнозирования температуры ликвидус хромоникелевых сталей была дополнительно проэкзаменована на независимых данных, которые не вошли в исходную выборку (рис.2.).

Использование концепции направленной химической связи позволило установить, что при прогнозировании температур солидус хромоникелевых сталей (рис.3) сохраняется влияние параметров $\mathrm{Z}^{\mathrm{y}}, \mathrm{d}, \operatorname{tg} \alpha$ аналогично моделированию температур плавления и модель имеет вид: $\mathrm{T}_{\mathrm{S}}=f\left(\mathrm{Z}^{\mathrm{y}}, \mathrm{d}, \operatorname{tg} \alpha\right)$ и точностью прогноза $\mathrm{R}^{2}=0,7985$.

Таблица 2

Данные экспериментальных и расчетных значений хромоникелевых сталей, не вошедших в исходную выборку

\begin{tabular}{|c|c|c|}
\hline Сталь & Т ликв экспер & Т ликв расч \\
\hline 20XH3A & 1510 & 1514.228 \\
\hline 08X18H10T & 1446 & 1442.115 \\
\hline 12X18H10T & 1459 & 1448.361 \\
\hline $20 \times 13$ & 1498 & 1498.901 \\
\hline 10Х18Н9ТЛ & 1457 & 1454.141 \\
\hline Ошибка прогноза, \% & \multicolumn{2}{|l|}{0.003} \\
\hline
\end{tabular}

Как следует из сопоставительного анализа, экспериментальных и расчетных данных температур плавления для хромоникелевых сталей, которые не вошли в исходную выборку характеризуются хорошей согласованностью (табл.2).

Высокая точность прогноза моделей, позволяет рекомендовать их для использования в системах АСУТП при решении задач выбора эффективного легирующего элемента и его усвоения.

\section{Выводы}

В работе предложены полуэмпирические прогнозные модели для определения температур плавления и кристаллизации хромоникелевых сталей на основе концепции направленной химической связи. Высокая точность моделей ппозволяет рекомендовать их для использования в системах АСНИ и АСУТП сталеплавильного производства.

\section{ЛИТЕРАТУРА}

1. Тогобицкая Д.Н. Микролегирование стали $14 \mathrm{X} 17 \mathrm{H} 2$ бором в условиях ПАО "Днепроспецсталь" / Тогобицкая Д.Н., Пиптюк В.П., Кукса О.В., Козачек А.С., Лихачев Ю.М., Логозинский И.Н., Левин Б.А., Сальников А.С. // Металлургическая и горнорудная промышленность. - 2016. - № 1. - С.40 - 45.

2. Saeed N. Ghali, Hoda S. El-Faramawy, Mamdouh M. Eissa. Influence of Boron Additions on Mechanical Properties of Carbon Steel / Journal of Minerals and Materials Characterization and Engineering. - 2012. - № 11. - P. 995-999.

3. Камкина Л.В., Манидин В.С., Пройдак С.В. Физико-химические и технологические особенности производства экономнолегированных борсодержащих сталей. / Металлургическая и горнорудная промышленность. - 2015. - № 6 (297). - С.19 - 23.

4. Ibatov M.K., Issagulov A.Z., Kvon Sv. S., Kulikov V. Yu., Arinova S. K. / Boron microadditives effect on heat resisting properties of Cr-Ni-Fe based alloy. / METALURGIJA. - 2018. - Vol.57. - № 1-2. P. 139-141.

5. Парусов В.В., Сычков А.Б., Деревянченко И.В., Жигарев М.А. Новое применение бора в металлургии. / Вестник МГТУ и. Г.И. Носова. - 2005. - № 1 (9). - С.15 - 17. 
6. Гаврилин И.В. Плавление и кристаллизация металлов и сплавов / Владим. гос. ун-т. Владимир, 2000. 260 с.

7. Казачков И.П. Легирование стали. - К.: Техніка, 1982. - 120 с.

8. Макуров С.Л. Экспериментальное и расчетное определение температуры ликвидус сложнолегированных сталей / С.Л. Макуров // Вестник Приазов. гос. тех. ун-та: Сб. научн. Тр. Мариуполь, 2003. - Вып. № 13. - С. 46 - 49.

9. Скребцов А.М., Иванов Г.А., Кузьмин Ю.Д., Качиков А.С., Золотарева Е.В. Влияние температуры нагрева жидкого алюминиевого сплава на микроструктуру затвердевшего металла. Вестник Приазов. гос. тех. ун-та: Сб. научн. Тр. - Мариуполь, 2003. - Вып. № 13. - С. $138-142$.

10. Скребцов А.М. Жидкие металлы. Их свойства и строение. Учебное пособие для вузов. Мариуполь, ПГТУ. - 2010. - 252 с.

11. Приходько Э.В., Петров А.Ф. Физико-химические крнитерии для оценки степени микронеоднородности металлических расплавов. / Металлофизика и новейшие технологии. 1998. - T.20. - № 7. - С. 64 - 74.

12. Приходько Э.В. Эффективность комплексного легирования сталей и сплавов. - К.: Наукова думка, 1995. - 292 с.

\section{REFERENCES}

1. Togobitskaya D.N. Mikrolegirovanie stali 14H17N2 borom v usloviyah PAO "Dneprospetsstal" / Togobitskaya D.N., Piptyuk V.P., Kuksa O.V., Kozachek A.S., Lihachev Yu.M., Logozinskiy I.N., Levin B.A., Salnikov A.S. // Metallurgicheskaya i gornorudnaya promyishlennost. - 2016. - \# 1. - S.40 - 45 .

2. Saeed N. Ghali, Hoda S. El-Faramawy, Mamdouh M. Eissa. Influence of Boron Additions on Mechanical Properties of Carbon Steel / Journal of Minerals and Materials Characterization and Engineering. - 2012. - \# 11. - P. 995-999.

3. Kamkina L.V., Manidin V.S., Proydak S.V. Fiziko-himicheskie i tehnologicheskie osobennosti proizvodstva ekonomnolegirovannyih borsoderzhaschih staley. / Metallurgicheskaya i gornorudnaya promyishlennost. - 2015. - \# 6 (297). - S.19 - 23.

4. Ibatov M.K., Issagulov A.Z., Kvon Sv. S., Kulikov V. Yu., Arinova S. K. / Boron microadditives effect on heat resisting properties of Cr-Ni-Fe based alloy. / METALURGIJA. - 2018. - Vol.57. - \# 1-2. - P. 139-141.

5. Parusov V.V., Syichkov A.B., Derevyanchenko I.V., Zhigarev M.A. Novoe primenenie bora v metallurgii. / Vestnik MGTU i. G.I. Nosova. - 2005. - \# 1 (9). - S.15 - 17.

6. Gavrilin I.V. Plavlenie i kristallizatsiya metallov i splavov / Vladim. gos. un-t. Vladimir, 2000. 260 s.

7. Kazachkov I.P. Legirovanie stali. - K.: TehnIka, 1982. - 120 s.

8. Makurov S.L. Eksperimentalnoe i raschetnoe opredelenie temperaturyi likvidus slozhnolegirovannyih staley / S.L. Makurov // Vestnik Priazov. gos. teh. un-ta: Sb. nauchn. Tr. Mariupol, 2003. - Vyip. \# 13. - S. 46 - 49.

9. Skrebtsov A.M., Ivanov G.A., Kuzmin Yu.D., Kachikov A.S., Zolotareva E.V. Vliyanie temperaturyi nagreva zhidkogo alyuminievogo splava na mikrostrukturu zatverdevshego metalla. Vestnik Priazov. gos. teh. un-ta: Sb. nauchn. Tr. - Mariupol, 2003. - Vyip. \# 13. - S. 138 - 142.

10. Skrebtsov A.M. Zhidkie metallyi. Ih svoystva i stroenie. Uchebnoe posobie dlya vuzov. Mariupol, PGTU. - 2010. - $252 \mathrm{~s}$.

11. Prihodko E.V., Petrov A.F. Fiziko-himicheskie krniterii dlya otsenki stepeni mikroneodnorodnosti metallicheskih rasplavov. / Metallofizika i noveyshie tehnologii. - 1998. - T.20. - \# 7. - S. 64 - 74. 
12. Prihodko E.V. Effektivnost kompleksnogo legirovaniya staley i splavov. - K.: Naukova dumka, 1995. - $292 \mathrm{~s}$.

Received 26.01.18

\section{FORECASTING THE MELTING AND CRYSTALLIZATION TEMPERATURES OF CHROMIUM-NICKEL STEELS}

Currently, the most widely used methods of finishing steel on the chemical composition through the processes of doping as a single additive, and complex master alloys for the formation of the desired properties of metal products. In order to obtain qualitatively new characteristics of chromium-nickel steels, it is necessary to expand the range of alloying additives used, taking into account the efficiency of their assimilation. Certainly, the selection of injected additives in steel refers to a complex multistage physicochemical process, which first of all should provide the conditions for the maximum degree of assimilation and uniform distribution of the seated master alloy with minimal energy and raw materials losses. The temperature factor is one of the most important catalysts for the assimilation of alloying, modifying and refining additives, the effectiveness of the reactions and the distribution of the leading elements between the metal and slag, as well as the most informative indicator for making decisions on the management of the temperature melting mode. Based on the structural features of metal melts, an idea was put forward on the approach to the choice of alloying additives with regard to their microheterogeneity. The paper proposed mathematical models for predicting liquidus and solidus temperatures of nickelchrome steels using the concept of a targeted chemical bond. The research results are recommended for use in industrial conditions with the purpose of a scientifically-based selection of alloying elements and the directional formation of the final product, which will reduce energy costs by integrating the developed models into the process control system of steelmaking.

Keywords: chromium-nickel steels, parameters of interatomic interaction, microalloying, liquidus and solidus temperatures, forecasting.

\section{ПРОГНОЗУВАННЯ ТЕМПЕРАТУР ПЛАВЛЕННЯ ТА КРИСТАЛІЗАЦІЇ ХРОМОНІКЕЛЕВИХ СТАЛЕЙ}

Грунтуючись на особливостях будови металевих розплавів висунута ідея про підхід до вибору легуючих добавок з урахуванням їх мікронеоднорідності. В роботі запропоновані математичні моделі для прогнозування температур ліквідус та солідус хромонікелевих сталей 3 використанням концепції спрямованого хімічного зв'язку. Результати досліджень рекомендуються до використання в промислових умовах з метою науково-обгрунтованого вибору легуючих добавок і спрямованого формування кінцевого продукту, що забезпечить зниження енергетичних витрат за допомогою інтеграції розроблених моделей в АСУТП сталеплавильного виробництва.

Ключові слова: хромонікелеві сталі, параметри міжатомної взаємодії, мікролегування, температура ліквідус та солідус, прогнозування.

Снігура Ірина Романівна - аспірант, молодший науковий співробітник, Інститут чорної металургії ім. 3.І. Некрасова НАН України.

Snigura Iryna - post-graduate student, junior researcher, Institute of Ferrous Metallurgy named after. Z.I. Nekrasov National Academy of Sciences of Ukraine.

Тогобицька Дар'я Миколаївна - д.т.н., професор, завідуюча відділом фізико-хімічних проблем металургійних процесів, старший науковий співробітник, Інститут чорної металургії ім. 3.І. Некрасова НАН України.

Togobitska Daria - Doctor of Technical Sciences, Professor, Head of the Department of Physical and Chemical Problems of Metallurgical Processes, Senior Researcher, Institute of Ferrous Metallurgy named after. Z.I. Nekrasov National Academy of Sciences of Ukraine. 